\title{
Patterns of complementary and alternative medicine use amongst outpatients in Tokyo, Japan
} Satoshi Hori*1,2, Iordan Mihaylov², Joana C Vasconcelos ${ }^{3}$ and Malcolm McCoubrie ${ }^{2}$

\author{
Address: ${ }^{1}$ Department of Urology, West Suffolk Hospital, Bury St. Edmunds, UK, ${ }^{2}$ Departments of Community and Mental Health, St George's, \\ University of London, UK and ${ }^{3}$ Centre for Applied Medical Statistics, Department of Public Health and Primary Care, University of Cambridge, UK \\ Email: Satoshi Hori* - satoshi@doctors.org.uk; Iordan Mihaylov - imihaylov@doctors.org.uk; Joana C Vasconcelos - jv284@medschl.cam.ac.uk; \\ Malcolm McCoubrie - malc@audnmalc.demon.co.uk \\ * Corresponding author
}

\section{Published: 23 April 2008}

BMC Complementary and Alternative Medicine 2008, 8:14 doi:10.1 186/1472-6882-8-14

This article is available from: http://www.biomedcentral.com/1472-6882/8/14

(C) 2008 Hori et al; licensee BioMed Central Ltd.

This is an Open Access article distributed under the terms of the Creative Commons Attribution License (http://creativecommons.org/licenses/by/2.0), which permits unrestricted use, distribution, and reproduction in any medium, provided the original work is properly cited.
Received: 2I January 2008

Accepted: 23 April 2008

\begin{abstract}
Background: The use of complementary and alternative medicine (CAM) has been increasing rapidly throughout the world during the past decade. The use of CAM in the general Japanese population has been previously reported to be as high as $76 \%$. This study aims to investigate the patterns of CAM use, perceived effectiveness and disclosure of CAM use to orthodox medical practitioners amongst patients attending typical primary and secondary care clinics in a busy district general hospital in Tokyo, Japan.
\end{abstract}

Methods: The authors analysed data collected during March 2002 on patients attending general outpatient clinics held at Shiseikai Daini Hospital in Tokyo, Japan. Data was collected by use of selfcompleted questionnaires distributed to patients in the outpatient clinics waiting area. Statistical analysis was performed using chi-square tests of independence.

Results: 515 adults were approached to participate in this study and the overall response rate was $96 \%(n=496) .50 \%$ of the patients were using or have used at least I CAM therapy within the last 12 months. The 5 most commonly used therapies were massage $(n=106,43 \%)$, vitamins $(n=85$, $35 \%)$, health foods including dietary supplements $(n=56,23 \%)$, acupressure $(n=51,21 \%)$ and kampo $(n=46,19 \%)$. The majority of CAM users $(75 \%, n=145)$ found their CAM treatment to be effective $(95 \% \mathrm{Cl}=68-81 \%)$. Patients who were more likely to use CAM were females $(p=$ $0.003)$ and those with a high number of medical conditions $(p=<0.000 \mathrm{I})$. Only a small proportion of patients reported their CAM use to their physician $(42 \%, n=74)$. There was no significant difference in CAM use for the different age groups $(p=0.85)$, education level $(p=0.30)$ and financial status $(p=0.82)$.

Conclusion: Patterns of CAM usage in the sample surveyed was high (50\%). Despite this high prevalence rate and presumed acceptance of CAM in Japan, the reporting of CAM use by patients to their physicians was low (42\%). It is therefore important that physicians are aware of the possibility that their patients may be using CAM and also increase their knowledge and understanding of these treatments. 


\section{Background \\ Definition of CAM}

The US National Centre for Complementary and Alternative Medicine (NCCAM) defines complementary and alternative medicine as a 'group of diverse medical and healthcare systems, practices and products that are not presently considered to be part of conventional medicine' [1]. CAM therapies can be classified broadly into five main categories (table 1 ).

\section{Use of CAM in Japan and around the world}

The use of CAM around the world has increased dramatically in recent times and is still on the increase [2-4]. The reported CAM usage in western countries such as Australia, Canada, Denmark, Norway, USA and UK ranges from $9 \%$ to $69 \%[2,3,5-10]$.

The use of CAM in the Far East is presumed to be higher than those of the West, as many of the well known CAM therapies originated from this region. The exact prevalence rates of CAM usage in individual far eastern countries is not well known as there have been substantially fewer well conducted population weighted surveys investigating this. It has been reported that $60 \%$ of people in Taiwan use traditional Chinese medicine, a form of CAM [11]. In Japan, $76 \%$ of the general population was found to be using some form of CAM [12].

The exact definition of what constitutes CAM however is culturally dependent. In India for example, arurveda is practiced on a nationwide scale and is commonly regarded as orthodox medicine. In China, traditional Chinese medicine such as herbal medicine, acupuncture, acupressure, qi gond and t'ai chi chu'an are widely practiced alongside modern western medicine. In Japan, kampo (traditional Japanese herbal medicine) and acupuncture are officially considered a CAM therapy but part of these costs are covered by the Japanese public health insurance. Some Japanese practitioners of kampo and acupuncture would therefore object to their inclusion in CAM and would regard themselves as belonging to the authentic traditional medicine [13]. Thus, the definition of CAM differs substantially from country to country. We have classified kampo and acupuncture as CAM in this study to allow comparison with other studies in international literature.
With increasing use of CAM worldwide, orthodox medical practitioners need to be aware of the potential use of CAM by patients. This is especially important in Japan as the general population already has a high baseline usage of CAM [12]. With increasing life expectancy and an ageing population, it is likely that a substantial number of Japanese patients presenting to orthodox medical practitioners will be using some form of CAM.

\section{The Japanese healthcare system}

Japan has a universal healthcare system in which individuals are covered either by the National Health Insurance scheme (for the self employed) or social insurance (for employees). Beneficiaries have to make some co-payments which are capped depending on income [14]. Provision of primary care in Japan is blurred with patients having the choice of visiting a community based primary care physician or a hospital outpatient clinic for assessment directly by a specialist without being charged a premium fee [15].

There have been a number of Japanese studies looking at the use of CAM in general practice $[16,17]$ or in specialist outpatient clinics such as oncology [18-20] but we are unaware of studies looking at the prevalence of CAM in patients presenting to a typical district general hospital (DGH) outpatient clinic offering both primary and secondary care services. In this study, we document the prevalence, user characteristics, reasons for use, perceived effectiveness and disclosure of CAM use to orthodox medical practitioners in patients attending the primary and secondary care clinics in a busy Tokyo hospital.

\section{Methods \\ Study population}

The study population consisted of patients attending the general outpatient clinics held at Shiseikai Daini Hospital in Tokyo, Japan. The study was conducted between 21/03/ 2002 to 29/03/2002. Shiseikai Daini Hospital is a busy 300 bed Tokyo Women's Medical University affiliated district general hospital located in Setagaya-ku in Tokyo, Japan. Tokyo consists of 23 municipalities (special wards) that make up the metropolis. Setagaya-ku is the largest special ward within Tokyo with a population of 820,652 people in 2001 (Japan census 2000).

\section{Table I: NCCAM Classification of CAM therapies}

I. Whole medical systems
2. Mind-body interventions
3. Biologically based therapies
4. Manipulative and body based methods
5. Energy therapies (Biofield therapies and bioelectomagnetic based
therapies)

Homeopathic medicine, naturopathic medicine, chiropractic, traditional Chinese medicine, Ayurveda etc.

Meditation, prayer, mental healing, art, dance, music therapy etc.

Herbs, vitamins, dietary supplements, Health foods, aromatherapy etc. Chiropractic or osteopathic manipulation, massage etc.

Reiki, Qi gong, therapeutic touch, electromagnetic fields etc. 


\section{Definition of CAM}

We defined CAM using the US National Center for Complementary and Alternative Medicine (NCCAM) definition as a 'group of diverse medical and healthcare systems, practices and products that are not presently considered to be part of conventional medicine'. This definition was consistently used when verbal explanation of CAM was requested by patients.

The CAM categories included in our questionnaire were chosen to be comparable with previous CAM studies $[4,21]$. Our questionnaire was further adapted to include CAM categories that we felt would be important in the Japanese setting [22-24].

\section{Conduct of study}

A two page semi-structured questionnaire consisting of 11 questions was initially developed in English. The questionnaire was then translated into Japanese by S.H. Parts of the questionnaire involved open-ended questions and all responses were analysed by S.H. The reliability and accuracy of the translation was tested by employing the back-translation method.

The draft Japanese questionnaire was piloted on 15 patients attending the general medical outpatient clinic at Shiseikai Daini Hospital on 20/03/2002 and some minor alterations were made prior to formally undertaking the survey. The two native Japanese speakers ( $\mathrm{SH}$ and $\mathrm{AH}$ ) distributing the questionnaires were calibrated prior to commencement of the study to ensure consistency in data recording and CAM definitions.

The questionnaire took on average 5 minutes to complete and included demographic data (age, sex, highest education level and financial status), current and past use of various CAM therapies within the last 12 months, current and past medical conditions suffered (within the last 3 years), reasons for using CAM therapies and its perceived efficacy and disclosure of CAM therapy use to their orthodox medical practitioner. Survey methods were approved by the research and ethics review board of Shiseikai Daini Hospital and strict confidentiality protocol was implemented and adhered to throughout the study.

Questionnaires were distributed twice daily to patients attending the adult general outpatient clinics run by the hospital and included the following specialties: obstetrics \& gynaecology, neurology, neurosurgery, orthopaedics, rheumatology, cardiology, gastroenterology, ear, nose \& throat, internal medicine, general surgery and dermatology. Specialist clinics such as oncology and pain clinics were not included in our survey. No specialty was canvassed more than twice daily. By covering all available non-specialist clinics and surveying these an equal number of times, we believe that we sampled a broad cross-section of patients attending these clinics.

The two native Japanese speakers ( $\mathrm{SH}$ and $\mathrm{AH}$ ) were in clear view of the respondents at all times to provide assistance upon request. In total, 515 adult patients were approached to participate and the overall response rate was $96 \%(n=496)$. The exclusion criteria for our study were patients' age (less than 18), patients attending specialist (tertiary) clinics and those who were unable to understand written or verbal instructions to complete the questionnaire. The age cutoff of 18 was chosen as this study was only analysing the adult population.

\section{Statistical analyses}

Univariate statistical analysis was performed using chisquare tests of independence ( $\chi^{2}$ test). A multi-variate analysis was also performed but this did not reveal any significant difference from the univariate analysis (data not shown). 95\% confidence intervals were determined and a p-value of $<0.05$ was considered statistically significant.

\section{Results}

515 adults were approached to participate in this study and the overall response rate was $96 \%(\mathrm{n}=496)$. Of the 496 patients included in this study, 38\% $(\mathrm{n}=190)$ were male and $62 \%(\mathrm{n}=306)$ were female with age ranging from 18 to 92 (Table 2).

$50 \%(\mathrm{n}=246 ; 95 \%$ C.I $45 \%$ to $54 \%)$ out of 496 patients questioned were using or have used at least 1 CAM therapy within the past 12 months (Table 3 ). The 5 most common CAM therapies used amongst the 246 patients were massage $(n=106,43 \%)$, vitamins $(n=85,35 \%)$, health food including dietary supplements $(\mathrm{n}=56,23 \%)$, acupressure $(n=51,21 \%)$ and kampo $(n=46,19 \%)$ - see figure 1.

\section{Patterns and Reasons of CAM use}

In our sampled population, women $(\mathrm{n}=168,55 \%)$ used more CAM than men $(\mathrm{n}=78,41 \%)(\mathrm{p}=0.003)$. Patients suffering from 3 or more medical conditions were more likely to use a higher number of CAM than those suffering from less than 3 medical conditions - see figure $2(\mathrm{p}=<$ $0.0001)$. There was no significant difference in CAM use amongst different age groups $(\mathrm{p}=0.85)$, in patients with higher educational level $(\mathrm{p}=0.30)$ and in patients who are financially better off $(\mathrm{p}=0.82)$ - see table 2 .

The majority of patients used CAM for a specific medical reason. The 3 commonest medical conditions for which CAM was used were musculo-skeletal $(\mathrm{n}=94,38 \%)$, gastro-intestinal $(\mathrm{n}=79,32 \%)$ and cardiac problems $(\mathrm{n}=76$, $31 \%)$. The 5 commonest CAM used were massage ( $\mathrm{n}=$ 
Table 2: Demographics of the population surveyed

\begin{tabular}{|c|c|c|c|c|c|c|}
\hline \multirow[t]{2}{*}{ Characteristic } & \multirow[t]{2}{*}{ Variable } & \multicolumn{2}{|c|}{$\begin{array}{l}\text { Sample } \\
(n=496)\end{array}$} & \multicolumn{2}{|c|}{$\begin{array}{l}\text { Users of CAM } 1 \\
\quad(n=246)\end{array}$} & \multirow[t]{2}{*}{ p-value ( $\chi^{2}$ test $)$} \\
\hline & & $\mathbf{n}=$ & $\%$ & $\mathbf{n}=$ & $\%$ & \\
\hline \multirow[t]{2}{*}{ Gender } & Male & 190 & 38 & 78 & 32 & 0.003 \\
\hline & Female & 306 & 62 & 168 & 68 & \\
\hline \multirow[t]{8}{*}{ Age } & $<20$ & 4 & 1 & 2 & 1 & $0.85^{*}$ \\
\hline & $20-29$ & 58 & 12 & 26 & 11 & \\
\hline & $30-39$ & 68 & 14 & 38 & 15 & \\
\hline & $40-49$ & 53 & II & 29 & 12 & \\
\hline & $50-59$ & 85 & 17 & 40 & 16 & \\
\hline & $60-69$ & 109 & 22 & 51 & 21 & \\
\hline & 70-79 & 83 & 17 & 42 & 17 & \\
\hline & $80+$ & 36 & 7 & 18 & 7 & \\
\hline \multirow[t]{4}{*}{ Highest education $\dagger$} & University degree & 155 & 31 & 77 & 31 & $0.30 *$ \\
\hline & Trade qualification & 109 & 22 & 56 & 23 & \\
\hline & Secondary school & 209 & 42 & 94 & 38 & \\
\hline & None (below secondary school) & 13 & 3 & 7 & 3 & \\
\hline \multirow[t]{3}{*}{ Financial status§ } & Not well off & 67 & 14 & 33 & 13 & $0.82^{*}$ \\
\hline & Average & 394 & 79 & 191 & 78 & \\
\hline & Well off & 30 & 6 & 15 & 6 & \\
\hline
\end{tabular}

* Linear-by-linear Association Chi-squared test ICAM use within the last 12 months

+10 patients $(2 \%)$ did not answer this question

$\$ 6$ patients ( $1 \%$ ) did not answer this question

$106,43 \%)$, vitamins ( $\mathrm{n}=85,35 \%)$, health food including dietary supplements $(\mathrm{n}=56,23 \%)$, acupressure $(\mathrm{n}=51$, $21 \%)$ and kampo $(n=46,19 \%)$. The commonest reasons given for using these CAMs are shown in table 4 .

\section{Perceived effectiveness and reporting of CAM use to their orthodox practitioner}

Out of the 246 patients who reported to have used at least 1 CAM during the past 12 months, 176 patients answered this question. Of these, only 74 patients (42\%) informed their orthodox medical practitioner about their use of CAM. 102 patients did not report their use of CAM to their physician $(58 \%)$. The majority of CAM users $(75 \%, \mathrm{n}=$ 145 out of 194) found their CAM treatment to be effective (95\% CI 68\%-81\%) ( $\mathrm{p}=0.005)$.

Table 3: Number of different CAMs used by individuals

\begin{tabular}{cc}
\hline Number of different CAMs used* & Number (\%) of people $\dagger$ \\
\hline 1 & $116(47 \%)$ \\
2 & $84(34 \%)$ \\
3 & $24(10 \%)$ \\
$4+$ & $22(9 \%)$
\end{tabular}

*within the last 12 months

†Total CAM users: 246

\section{Discussion}

This study investigated the use of CAM amongst a Japanese population attending the general outpatient clinics held at Shiseikai Daini Hospital in Tokyo, Japan. Half of those questioned (50\%) were using or have used at least 1 CAM therapy within the last 12 months.

The main aim of this study was to investigate whether or not the usage of CAM in patients attending a DGH general outpatient clinics differs from that of the general population but interestingly we found that the top 5 CAM used in our population were also the same as those used in the general Japanese population as reported by Yamashita et al, 2002 [12].

We found that female patients were more likely to use CAM than males ( $\mathrm{p}=0.003)$, and this is consistent with previous published findings [4,25-28]. We also found that patients with a high number of medical conditions tend to use more CAM than others $(\mathrm{p}=<0.0001)$. One explanation for this is that patients with more medical conditions will probably have had less success in treating their own health problems and their continued suffering may have prompted them to seek alternatives. Other studies have also shown that patients suffering from chronic diseases have a higher usage of CAM than those who don't [4,29-34]. 


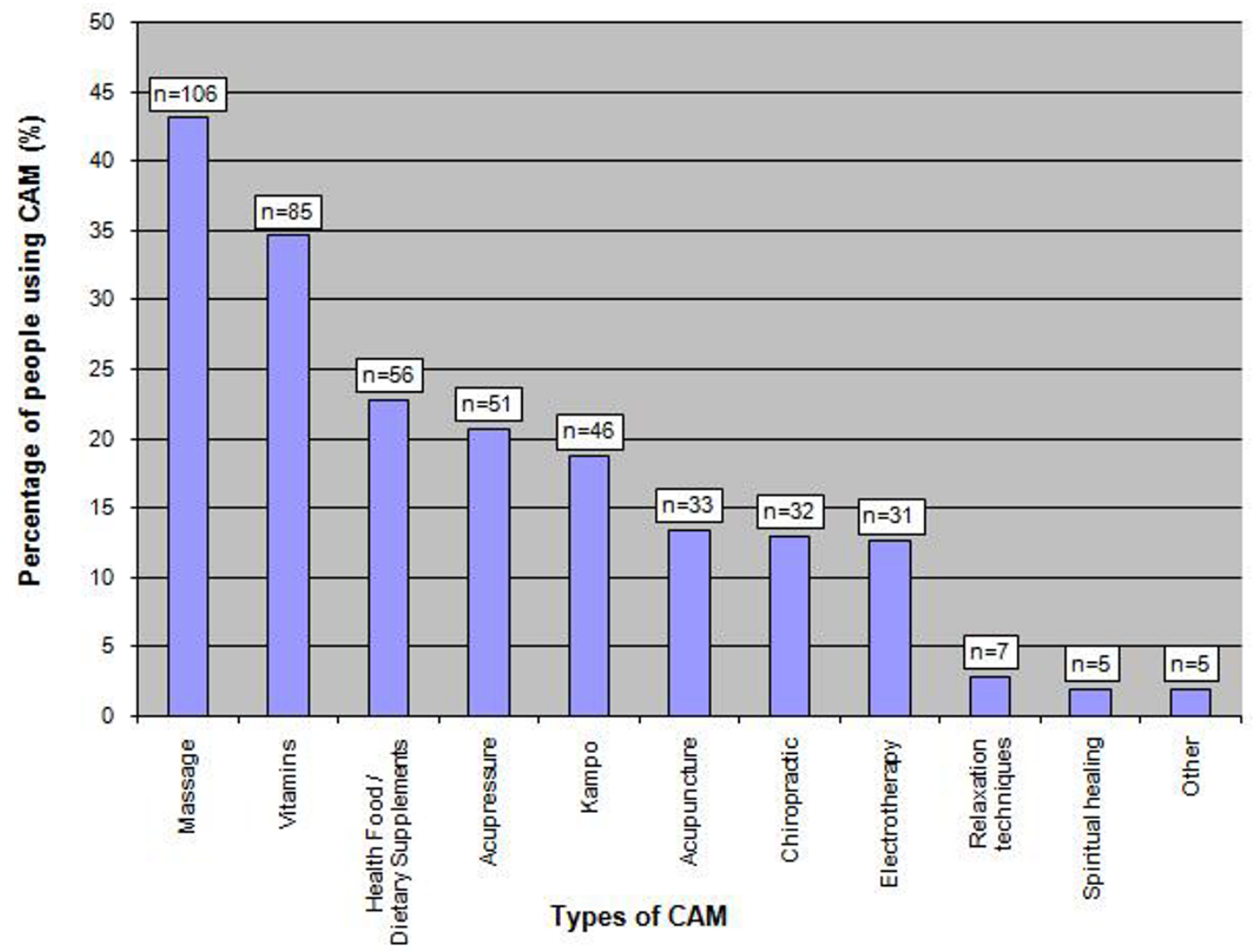

Figure I

Types of CAM used by patients during the past 12 months.

In the present study, musculo-skeletal problems emerged as the top reason for patients using CAM $(29 \%, n=71)$. Musculo-skeletal problems and pain are frequently inadequately treated by orthodox medical practitioners and thus becomes troubling and chronic for many patients, who are therefore more likely to use CAM [29,30,33-38]. Dissatisfaction with conventional orthodox medicine was not a great determinant of patients resorting to using CAM, with only $1 \%(n=6)$ of patients quoting this as a reason [39].

We found that most patients found their CAM to be of help ( $p=0.005)$. Despite this, only $42 \%(n=74)$ of the patients who responded to this question reported their use of CAM to their orthodox medical practitioner. This seemingly low percentage figure is in agreement with other studies $[4,5,35,40,41]$. It is somewhat surprising that with a high prevalence of CAM usage and presumed acceptance of CAM therapies in Japan, reporting of CAM usage by individuals to their orthodox medical practitioners was low. Our sample population consisted of those patients who were attending and seeking help from orthodox practitioners. Patients therefore may have found it hard to report their CAM use for fear of anticipating a negative response and disapproval from their doctor [35].

\section{Limitations of the study}

This study analysed a population of patients attending a typical busy Tokyo district general hospital outpatient department and is therefore not representative of the general population. By approaching consecutive outpatient presentations and systematically sampling the different specialities, the potential for sampling bias was minimised. Patients were asked to fill a questionnaire and to recall the use of CAM in the past year therefore they may have been subjected to recall bias.

Although our prevalence rate was high (50\%), it is lower than those reported by Yamashita et al in 2002 [12]. They reported a prevalence rate of $76 \%$. There are a number of reasons why their value might be higher than that found in this study. Firstly, Yamashita et al sampled a nation- 


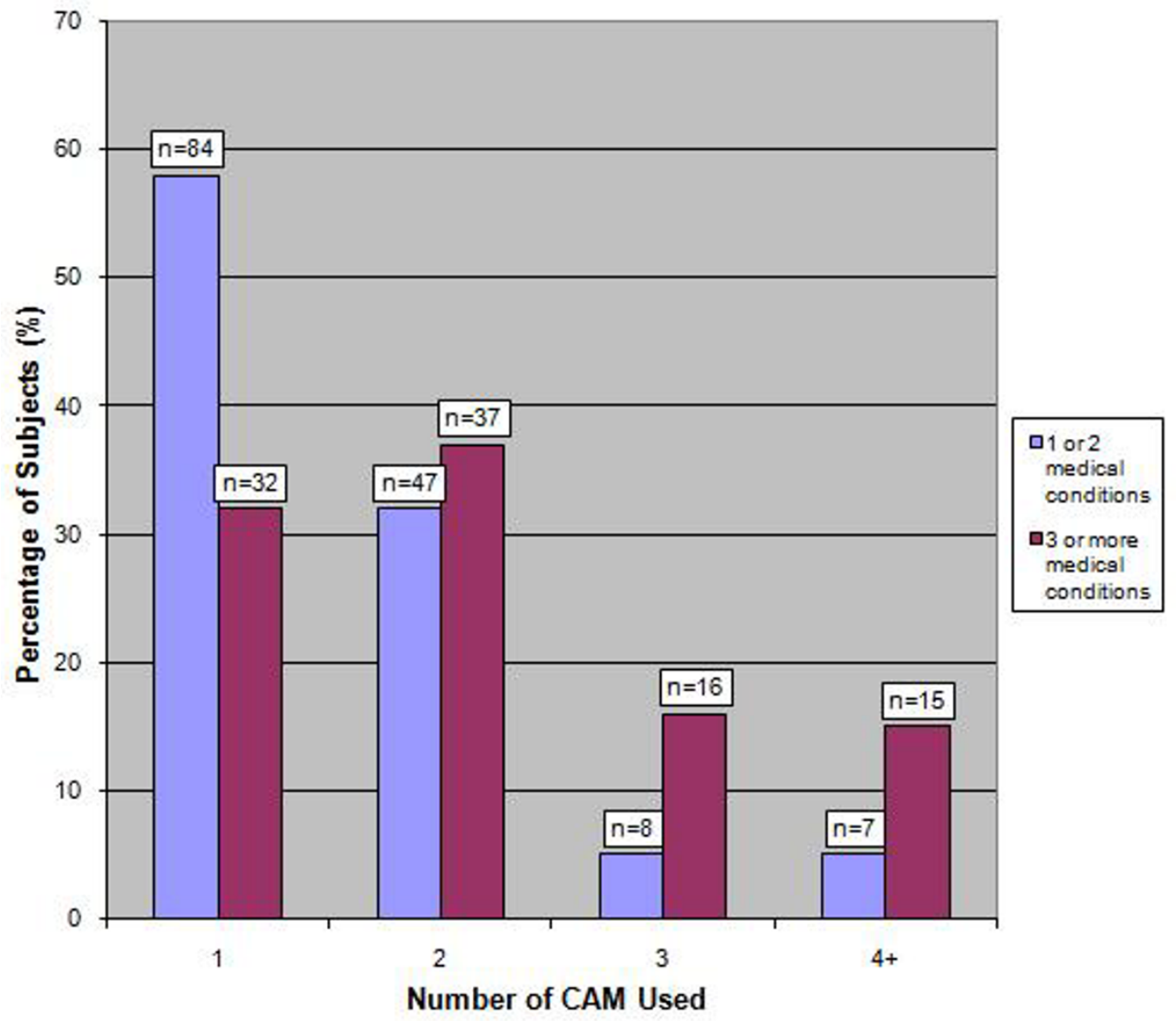

Figure 2

Patterns of CAM usage according to the number of medical conditions suffered.

wide, population weighed sample which is likely to be more representative of the general population compared to our study. Although we tried to minimise sampling bias with our methodology, people who attend hospital outpatient clinics are already a self selected group of patients who are attending these clinics for a specific medical reason. Thus the usage and reasons for CAM use in our patient group is different from that of the general population.

Secondly, the definition of CAM used in this study differed from that used by Yamashita et al (2002) and this may account for the difference in the prevalence rate. However, in order to allow our results to be compared to other studies in the international literature, the CAM categories included in our questionnaire were chosen to be comparable with previous CAM studies [4,21]. We further included CAM categories that we felt would be important in the Japanese setting [22-24].
Unlike previously reported [25], we have not found higher education level to be associated with a higher usage of CAM ( $p=0.30)$. One of the reasons why we may not have found a significant difference in education being associated with CAM use may be because only 3\% ( $\mathrm{n}=$ 13) of our responders left education at secondary school level and below. This figure is considerably lower than that of the Japan census (2000) where $26.6 \%$ of the Japanese population was reported to have an education level of secondary school level and below. An explanation is that those who attend hospital outpatient clinics are patients who are more health conscientious and therefore more likely to have a higher level of education [42].

Financial status also failed to reveal any significant difference ( $p=0.82)$, contrary to those reported by Wiles and Rosenberg [25]. Japan, unlike many other countries, lacks the distinct boundaries that exist between different social classes. Significant number of Japanese people are middle class or above and this may explain in part the reason why financial status did not predict the usage of CAM. Another 
Table 4: Commonest reasons given for using the 5 most popular CAMs

\begin{tabular}{|c|c|c|c|}
\hline Type of CAM & Specific reasons stated for using CAM & $\%(n)$ & 95\% C.I* \\
\hline \multirow[t]{3}{*}{ Massage $(n=106)$} & Musculo-skeletal problems & $47 \%(50)$ & $37 \%$ to $57 \%$ \\
\hline & Recommended by friend & $7 \%(7)$ & $3 \%$ to $13 \%$ \\
\hline & Neurological problems & $5 \%(5)$ & $2 \%$ to $11 \%$ \\
\hline \multirow[t]{3}{*}{ Vitamins $(n=85)$} & Musculo-skeletal problems & $19 \%(16)$ & II\% to $29 \%$ \\
\hline & General wellbeing & $14 \%(12)$ & $8 \%$ to $23 \%$ \\
\hline & To get better & $9 \%(8)$ & $4 \%$ to $18 \%$ \\
\hline \multirow[t]{3}{*}{ Health food/dietary supplement $(n=56)$} & Musculo-skeletal problems & $21 \%(12)$ & $12 \%$ to $34 \%$ \\
\hline & General wellbeing & $16 \%(9)$ & $8 \%$ to $28 \%$ \\
\hline & To get better & $13 \%(7)$ & $5 \%$ to $24 \%$ \\
\hline \multirow[t]{3}{*}{ Acupressure $(n=5 I)$} & Musculo-skeletal problems & $35 \%(18)$ & $22 \%$ to $50 \%$ \\
\hline & Recommended by friend & $10 \%(5)$ & $3 \%$ to $21 \%$ \\
\hline & General wellbeing & $6 \%(3)$ & $1 \%$ to $16 \%$ \\
\hline \multirow[t]{3}{*}{ Kampo $(n=46)$} & Musculo-skeletal problems & $15 \%(7)$ & $6 \%$ to $29 \%$ \\
\hline & Gynaecological problems & $13 \%(6)$ & $5 \%$ to $26 \%$ \\
\hline & Lack of perceived side effects & $11 \%(5)$ & $4 \%$ to $24 \%$ \\
\hline
\end{tabular}

$* C . I=$ Confidence Interval

reason may be the way in which financial status was analysed in this study. We asked patients whether they thought they were "not well off, average or well off". Patients may be reluctant to admit their real financial status and thus may write down "average" as a default answer. A better method to survey this would have been to ask patients to reveal their income; however this might have made people more reluctant to participate in this study and thus decrease the overall completion rate.

A number of questions within the survey were noted to have a lower response rate than others. Questions relating to highest educational level, financial status and CAM use reporting to their orthodox medical practitioner were noted to be such cases. It is reasonable to expect this, as many people do not wish to disclose this more intimate data. Nevertheless, we felt that we had enough respondents to justify these results being included in our analysis.

\section{Applicability of the study}

Despite these limitations, there are a number of important findings in this study. We have found that a high proportion of Japanese patients who attend hospital outpatient clinics use CAM and do not disclose this fact to their doctors. This is important in the Japanese setting where provision of primary care in Japan is blurred with patients having the choice of visiting a community based primary care physician or a hospital outpatient clinic for assessment directly by a specialist [15]. Orthodox practitioners should be aware that their patients may be using CAM and should routinely enquire about this during consultation.
Although CAM is often seen by patients as the "healthy alternative with low or no side effect profile", numerous papers have highlighted the possible side effects of certain CAM therapies. There is a risk of tissue trauma and infection from acupuncture and carcinogenic potential of some aromatherapy oils. The herbs St John's wort and Gingko biloba carry a risk of bleeding and risk of interactions with many drugs. Reports of mechanical injury following acupuncture leading to pneumothorax, cardiac tamponade and spinal cord injury have all been reported [21,43-51]. With increasing CAM popularity, it is important that orthodox medical practitioners are aware of these potential side effects posed by the usage of CAM and should routinely enquire patients regarding CAM use.

\section{Conclusion}

This present study showed that $50 \%$ of patients surveyed were currently using or have used at least 1 CAM therapy within the last 12 months. Socio-demographic variables did not predict use, and reported use of CAM to orthodox practitioners was low and perceived effectiveness was high. It is of paramount importance therefore that doctors increase their understanding and awareness of potential CAM usage by their patients.

\section{Competing interests}

The authors declare that they have no competing interests.

\section{Authors' contributions}

SH came up with the original idea. SH and IM contributed equally in obtaining the completed questionnaires and analysing the data. JCV double checked the results and 
performed the statistical analysis. MM participated in the design and coordination of the study and helped to draft the manuscript. All authors read and approved the final manuscript.

\section{Acknowledgements}

The authors would like to thank all the staff at Shiseikai Daini Hospital and in particular Dr Michiko Kaneko and Dr Sayuri Aiba, for their kind hospitality and support throughout our stay in Tokyo. We would also like to thank Mr A. Hiraoka, for all his dedication and help in collating the data. We thank Dr Toby Prevost (Centre for Applied Medical Statistics, University of Cambridge) for his help with the statistics. Finally, we would like to thank Dr Lisa Ko for proof reading the manuscript.

\section{References}

I. National Center for Complementary and Alternative Medicine [http://nccam.nih.gov/]

2. Harris $P$, Rees $R$ : The prevalence of complementary and alternative medicine use among the general population: a systematic review of the literature. Complement Ther Med 2000, 8(2):88-96.

3. Ernst E: Prevalence of use of complementary/alternative medicine: a systematic review. Bull World Health Organ 2000 , 78(2):252-257.

4. Tindle HA, Davis RB, Phillips RS, Eisenberg DM: Trends in use of complementary and alternative medicine by US adults: 1997-2002. Altern Ther Health Med 2005, I I(I):42-49.

5. Xue CC, Zhang AL, Lin V, Da Costa C, Story DF: Complementary and alternative medicine use in Australia: a national population-based survey. J Altern Complement Med 2007, I 3(6):643-650.

6. Ernst $E$, White $A$ : The BBC survey of complementary medicine use in the UK. Complement Ther Med 2000, 8(I):32-36.

7. Millar W]: Use of alternative health care practitioners by Canadians. Can J Public Health 1997, 88(3): I54-158.

8. Hanssen B, Grimsgaard S, Launso L, Fonnebo V, Falkenberg T, Rasmussen NK: Use of complementary and alternative medicine in the Scandinavian countries. Scand J Prim Health Care 2005, 23(1):57-62.

9. Thomas K, Coleman P: Use of complementary or alternative medicine in a general population in Great Britain. Results from the National Omnibus survey. J Public Health (Oxf) 2004, 26(2): $152-157$.

10. Wolf U, Maxion-Bergemann S, Bornhoft G, Matthiessen PF, Wolf M: Use of complementary medicine in Switzerland. Forsch Kom plement Med 2006, I 3(Suppl 2):4-6.

II. Chen FP, Chen TJ, Kung YY, Chen YC, Chou LF, Chen FJ, Hwang SJ: Use frequency of traditional Chinese medicine in Taiwan. BMC Health Serv Res 2007, 7:26.

12. Yamashita H, Tsukayama H, Sugishita C: Popularity of complementary and alternative medicine in Japan: a telephone survey. Complement Ther Med 2002, 10(2):84-93.

13. Suzuki N: Complementary and Alternative Medicine: a Japanese Perspective. Evid Based Complement Alternat Med 2004, I(2): II3-II 8

14. Fukawa T: Public health insurance in Japan. Washington, DC: World Bank Institute; 2002

15. Nomura H, Nakayama T: The Japanese healthcare system. $B M$ J 2005, 33 I (75 I 8):648-649.

16. Uemura $\mathrm{H}$ : Heterogeneity among complementary and alternative therapies- results of a survey of outpatients in Japanese general practices. Journal of Kyoto Prefectural University of Medicine 2004, II 3(5):285-294

17. Tsuruoka Y, Tsuruoka K, Long S, Kajii E: Understanding the Use of Complementary and Alternative Medicine (CAM) in Japanese Primary Care: A Qualitative Study. Japanese Journal of Primary Care 2006, 29(I): I5-2I.

18. Hyodo I, Amano N, Eguchi K, Narabayashi M, Imanishi J, Hirai M, Nakano T, Takashima S: Nationwide survey on complementary and alternative medicine in cancer patients in Japan. J Clin Oncol 2005, 23( I 2):2645-2654.

19. Hirai K, Komura K, Tokoro A, Kuromaru T, Ohshima A, Ito T, Sumiyoshi $\mathrm{Y}$, Hyodo I: Psychological and behavioral mechanisms influencing the use of complementary and alternative medicine (CAM) in cancer patients. Ann Oncol 2008, 19(1):49-55.

20. Yoshimura K, Ueda N, Ichioka K, Matsui Y, Terai A, Arai Y: Use of complementary and alternative medicine by patients with urologic cancer: a prospective study at a single Japanese institution. Support Care Cancer 2005, 13(9):685-690.

21. Ernst $E:$ The role of complementary and alternative medicine. BMJ 2000, 32 I(7269): I I33-I I 35.

22. Imanishi J, Watanabe S, Satoh M, Ozasa K: Japanese doctors' attitudes to complementary medicine. Lancet 1999 , 354(9191): 1735-1736

23. Watanabe S, Imanishi J, Satoh M, Ozasa K: Unique place of Kampo (Japanese traditional medicine) in complementary and alternative medicine: a survey of doctors belonging to the regional medical association in Japan. Tohoku J Exp Med 200I, 194(1):55-63.

24. Kamohara S: In Alternative Medicine. Ist edition. Tokyo: Tyuou Kouron Shinsha; 2002:30-35.

25. Wiles J, Rosenberg MW: 'Gentle caring experience'. Seeking alternative health care in Canada. Health Place 200I, 7(3):209-224.

26. Conboy L, Patel S, Kaptchuk TJ, Gottlieb B, Eisenberg D, AcevedoGarcia D: Sociodemographic determinants of the utilization of specific types of complementary and alternative medicine: an analysis based on a nationally representative survey sample. J Altern Complement Med 2005, I I (6):977-994.

27. Fukuda S, Watanabe E, Ono N, Tsubouchi M, Shirakawa T: Use of complementary and alternative medicine and health problems. Nippon Koshu Eisei Zasshi 2006, 53(4):293-300.

28. Al-Windi A: Determinants of complementary alternative medicine (CAM) use. Complement Ther Med 2004, I2(23):99-1II.

29. Barnes PM, Powell-Griner E, McFann K, Nahin RL: Complementary and alternative medicine use among adults: United States, 2002. Adv Data 2004:I-19.

30. Fleming S, Rabago DP, Mundt MP, Fleming MF: CAM therapies among primary care patients using opioid therapy for chronic pain. BMC Complement Altern Med 2007, 7:15.

31. Kaboli PJ, Doebbeling BN, Saag KG, Rosenthal GE: Use of complementary and alternative medicine by older patients with arthritis: a population-based study. Arthritis Rheum 200I, 45(4):398-403.

32. Rao JK, Mihaliak K, Kroenke K, Bradley J, Tierney WM, Weinberger $M$ : Use of complementary therapies for arthritis among patients of rheumatologists. Ann Intern Med 1999, I3 I (6):409-416.

33. Chenot JF, Becker A, Leonhardt C, Keller S, Donner-Banzhoff N, Baum E, Pfingsten M, Hildebrandt J, Basler HD, Kochen MM: Use of complementary alternative medicine for low back pain consulting in general practice: a cohort study. BMC Complement Altern Med 2007, 7:42.

34. Kajiyama H, Akama H, Yamanaka H, Shoji A, Matsuda Y, Tanaka E, Nakajima A, Terai C, Hara M, Tomatsu T, Saitoh T, Kamatani N: One third of Japanese patients with rheumatoid arthritis use complementary and alternative medicine. Mod Rheumatol $2006,16(6): 355-359$

35. Cauffield JS: The psychosocial aspects of complementary and alternative medicine. Pharmacotherapy 2000, 20(I I): I 289-I 294.

36. Artus $M$, Croft $P$, Lewis $M$ : The use of $C A M$ and conventional treatments among primary care consulters with chronic musculoskeletal pain. BMC Fam Pract 2007, 8:26

37. Lee GB, Charn TC, Chew ZH, Ng TP: Complementary and alternative medicine use in patients with chronic diseases in primary care is associated with perceived quality of care and cultural beliefs. Fam Pract 2004, 2 I (6):654-660.

38. Wainapel SF, Thomas AD, Kahan BS: Use of alternative therapies by rehabilitation outpatients. Arch Phys Med Rehabil 1998, 79(8): $1003-1005$

39. Astin JA: Why patients use alternative medicine: results of a national study. JAMA 1998, 279(19): I548-I553.

40. Flaherty JH, Takahashi R, Teoh J, Kim JI, Habib S, Ito M, Matsushita S: Use of alternative therapies in older outpatients in the United States and Japan: prevalence, reporting patterns, and perceived effectiveness. J Gerontol A Biol Sci Med Sci 200I, 56(10):M650-655. 
4I. Lee MS, Yang CY, Lee SI, Joo MC, Shin BC, Yoo WH, Shin YI: Use of complementary and alternative medicine by rheumatoid arthritis patients in Korea. Clin Rheumatol 2008, 27(I):29-33.

42. Wardle J, Steptoe A: Socioeconomic differences in attitudes and beliefs about healthy lifestyles. J Epidemiol Community Health 2003, 57(6):440-443.

43. Niggemann B, Gruber C: Side-effects of complementary and alternative medicine. Allergy 2003, 58(8):707-716.

44. Peuker ET, White A, Ernst E, Pera F, Filler TJ: Traumatic complications of acupuncture. Therapists need to know human anatomy. Arch Fam Med 1999, 8(6):553-558.

45. MacPherson $\mathrm{H}$, Thomas $\mathrm{K}$, Walters S, Fitter M: The York acupuncture safety study: prospective survey of $\mathbf{3 4} 000$ treatments by traditional acupuncturists. BMJ 200I, 323(73 I I):486-487.

46. Norheim AJ: Adverse effects of acupuncture: a study of the literature for the years 198I-1994. J Altern Complement Med 1996, 2(2):29|-297.

47. White A, Hayhoe S, Hart A, Ernst E: Adverse events following acupuncture: prospective survey of 32000 consultations with doctors and physiotherapists. BMJ 200I, 323(73 II):485-486.

48. Bensoussan A, Myers SP, Carlton AL: Risks associated with the practice of traditional Chinese medicine: an Australian study. Arch Fam Med 2000, 9(10): 1071-1078.

49. Mazal DA, King T, Harvey J, Cohen J: Bilateral pneumothorax after acupuncture. $N$ Engl J Med 1980, 302(24): 1365-I366.

50. Cheng TO: Cardiac tamponade following acupuncture. Chest 2000, I I 8(6): 1836-1837.

5I. Kirchgatterer A, Schwarz CD, Holler E, Punzengruber C, Hartl P, Eber B: Cardiac tamponade following acupuncture. Chest 2000, II7(5): $1510-1511$.

\section{Pre-publication history}

The pre-publication history for this paper can be accessed here:

http://www.biomedcentral.com/1472-6882/8/14/prepub

Publish with Biomed Central and every scientist can read your work free of charge

"BioMed Central will be the most significant development for disseminating the results of biomedical research in our lifetime. "

Sir Paul Nurse, Cancer Research UK

Your research papers will be:

- available free of charge to the entire biomedical community

- peer reviewed and published immediately upon acceptance

- cited in PubMed and archived on PubMed Central

- yours - you keep the copyright

Submit your manuscript here:

http://www.biomedcentral.com/info/publishing_adv.asp
BiolMedcentral 